\title{
Perencanaan strategis sistem informasi menggunakan Enterprise Architecture Planning pada PT. Karya Cipta Buana Sentosa Maumere
}

\author{
Salahudin Robo a, Trisno Trisno ${ }^{b}$, Sunardi Sunardi c, Santosa Santosa ${ }^{d}$ \\ a,d Teknik Informatika, Universitas Muhammadiyah Maluku Utara, Ternate, Indonesia \\ ${ }^{b}$ Teknik Informatika, Sekolah Tinggi Manajemen Informatika Komputer Uyelindo Kupang, Kupang, Indonesia \\ 'Teknik Informatika, Universitas Nahdlatul Ulama Nusa Tenggara Barat, Mataram, Indonesia \\ email:asalahudinrobo759@gmail.com,btrisnomtf@gmail.com,csoenardhi.75@gmail.com,dmhdsantosa@gmail.com
}

\begin{tabular}{l}
\hline I N F O A R T I K E L \\
\hline Sejarah artikel: \\
Menerima 20 Mei 2018 \\
Revisi 9 Agustus 2018 \\
Diterima 10 Agustus 2018 \\
Online 10 Agustus 2018 \\
\hline Kata kunci: \\
EAP \\
perencanaan strategis \\
value chain
\end{tabular}

Keywords:

\section{EAP}

strategic planning

value chain

\footnotetext{
Style APA dalam mensitasi artikel ini:

Robo, S., Trisno, T., Sunardi,

S., \& Santosa, S. (2018)

Perencanaan strategis sistem informasi menggunakan Enterprise Architecture Planning pada PT. Karya Cipta Buana Sentosa Maumere. Register: Jurnal Ilmiah Teknologi Sistem Informasi, 4(1), 41-48.
}

\begin{abstract}
ABSTRAK
Teknologi informasi semakin lama semakin maju dan setiap saat selalu ada perkembangannya yang berpengaruh terhadap berbagai aspek kehidupan. Salah satu diantaranya adalah aspek perekonomian yang berdampak positif bagi perusahaan. Oleh karena itu, setiap perusahaan berusaha untuk menerapkan teknologi informasi dengan tujuan meningkatkan efektifitas dalam proses bisnis, agar perusahan mampu memberikan nilai tambah yaitu berupa keunggulan dalam persaingan bisnis. Enterprise Architecture Planning (EAP) merupakan suatu metode pendekatan dalam perencanaan kualitas data yang berorientasi pada kebutuhan bisnis, perencanaan ini terdiri dari arsitektur data, aplikasi dan infrastruktur teknologi. Tujuan dari penelitian ini untuk menghasilkan proses bisnis perusahaan agar berjalan lebih efektif. Pemodelan bisnis yang digunakan pada penelitian menggunakan analisis value chain. Penggunaan value chain untuk mengetahui jenis-jenis kegiatan serta aktifitas yang ada dalam perusahaan, usulan atau rekomendasi sistem informasi tersebut ditunjukan untuk manager perusahaan terkait sesuai dengan visinya. Hasil dari penelitian ini untuk meningkatkan penyelarasan bisnis dan teknologi informasi pada perusahaan.
\end{abstract}

\section{ABSTRACT}

\begin{abstract}
Information technology is getting more advanced and always have a developing affects to various aspects of life. One of them is the aspect of economy that positively impacts the company. As the results, each company attempts to apply the information technology to improve the effectiveness in the business processing, so that company can give the added value such as the predominance in business competition. Enterprise Architecture Planning or EAP is a method of data quality planning approach that is oriented to business needs consisting of data architecture, application and technology infrastructure. The purpose of this study is to produce business processes of the company to run it more effectively. Business modeling that applied in this research is value chain analysis. The used of value chain is to know the type of activities that exist within the company. The proposed information system is addressed to the manager of related company in accordance with its vision.
\end{abstract}

(C) 2018 Register: Jurnal IImiah Teknologi Sistem Informasi. Semua hak cipta dilindungi undang-undang

\section{Pendahuluan}

Teknologi Informasi (TI) semakin lama semakin maju, setiap saat selalu ada perkembangan yang berpengaruh terhadap berbagai aspek kehidupan. Salah satu diantaranya adalah aspek perekonomian yang berdampak positif bagi perusahaan. Oleh karena itu, setiap perusahaan berusaha untuk menerapkan TI dengan tujuan meningkatkan efektifitas dalam proses bisnis, agar perusahan mampu memberikan nilai tambah berupa keunggulan dalam persaingan bisnis (Lin \& Dyck, 2010) (Rajabi \& Abade, 2012) (Kristanto, 2016) (Wiyana \& Winarno, 2015). 
Dengan berkembangnya TI saat ini, menuntut perusahaan untuk menjadikan TI sebagai salah satu strategis perusahaan (Mualo \& Budiyanto, 2016). Perusahaan-perusahaan sekarang banyak yang mengandalkan TI untuk mendukung strategi bisnisnya (Riku \& Setyohadi, 2017). Bahkan ada juga perusahaan yang telah menjadikan TI sebagai strategi utama untuk mencapai tujuan perusahaan, baik keuntungan ataupun kelangsungan usaha perusahaan, serta dalam rangka membangun citra perusahaan yang baik, maka perusahaan tersebut perlu menerapkan beberapa strategi dalam berbisnis (Budiyanto \& Setyohadi, 2017) (Rajabi \& Abade, 2012). Strategi tersebut dapat melibatkan seluruh komponen, pelaku bisnis sumber daya internal perusahaan secara berkesinambungan dengan memanfaatkan perkembangan TI dalam bidang usaha untuk memperoleh sistem yang efektif dan efisiensi.

PT. KCBS (Karya Cipta Buana Sentosa) adalah salah satu pusat pemasaran penjualan dan pendistribusian ikan yang dihasilkan oleh para nelayan Flores, khususnya kabupaten Sikka kota Maumere. Selain untuk konsumsi lokal, juga dapat didistribusikan ke luar daerah maupun diekspor. Perusahaan ini telah berdaya saing dengan perusahaan-perusahaan lainnya, karena menghasilkan ikan untuk diekspor maupun untuk konsumsi dalam negeri sebanyak 150-300 ton perbulannya. PT. KCBS sampai saat ini belum mendukung proses bisnis yang memanfaatkan TI. Kondisi teknologi yang ada pada PT. KCBS sampai saat ini dalam pengelolaannya masih bersifat manual, oleh sebab itu dibutuhkan suatu perencanaan strategis terkait dengan sistem informasi, tujuannya adalah agar proses perjalanan bisnis perusahaan berjalan lebih efektif. Untuk proses strategi informasi dapat berjalan dengan baik diperlukan metode.

Dalam proses perencanaan strategis terdapat beberapa metode yang sering digunakan, seperti Enterprise Architecture Planning (EAP), TOGAF, DODAF dan Federal enterprise Architecture (FEA). Pada peniltian ini, metode yang digunakan adalah EAP, hal ini dikarenakan metode tersebut memiliki keunggulan lebih, dalam hal adaptasi dan alat-alat pendukung (Nikpay, Ahmad, Rouhani, Mahrin, \& Shamshirband, 2017).

EAP merupakan suatu metode pendekatan dalam perencanaan kualitas data yang berorientasi pada kebutuhan bisnis, perencanaan ini terdiri dari arsitektur data, aplikasi dan infrastruktur teknologi, bagaimana cara untuk mengimplementasikan data? Arsitektur tersebut dalam usaha untuk mendukung berjalannya suatu bisnis dan pencapaian agar tercapainya tujuan dari organisasi (Gomes, 2015) (Mezzanotte \& Dehlinger, 2014). Selain hal tersebut, metode ini sering digunakan untuk meningkatkan penyelarasan bisnis dan TI suatu perusahaan (Simon, Fischbach, \& Schoder, 2014) (Hinkelmann \& Pasquini, 2014) (Kurniawan \& Suhardi, 2013). Keuntungan menggunakan EAP adalah penggunaan teknologi yang bersifat strategis untuk mengelola data sebagai sebuah aset dari organisasidan dapat dijalankan untuk penilaian terhadap dampak perubahan bisnis.

\section{Tinjauan Pustaka}

\subsection{Enterprise Arschitecture Planning (EAP)}

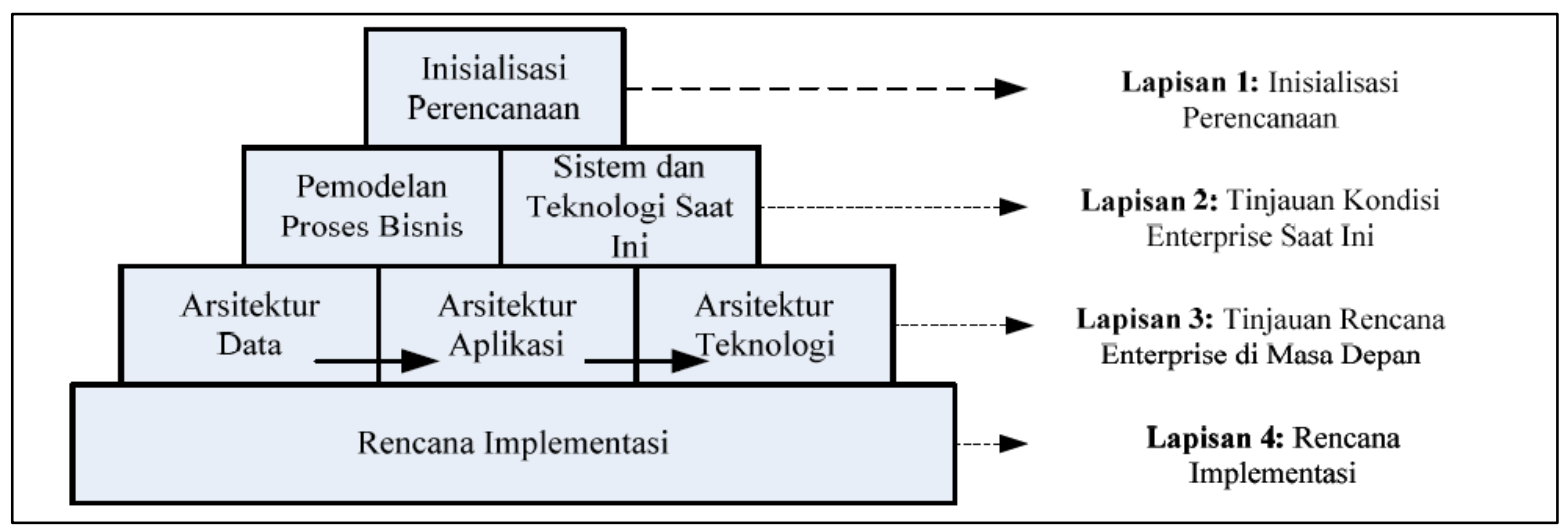

Gambar 1. Lapisan EAP (Spewak \& Hill, 1993)

Enterprise Arschitecture Planning (EAP) adalah sebuah metode yang diperkenalkan oleh Spewak dan Hill (1993). EAP adalah proses pendefinisian arsitektur dalam penggunaan informasi untuk mendukung proses bisnis dan rencana yang mengimplementasikan arsitektur tersebut (Korhonen \& Molnar, 2014). Metode EAP ini berisi kegiatan dan proses untuk mencapai arsitektur dengan mempertimbangkan 
empat arsitektur EA, ke empat arsitektur tersebut yaitu: Bisnis, data, aplikasi dan infrastruktur (Nikpay, Ahmad, Rouhani, Mahrin, \& Shamshirband, 2017). Keempat arsitektur tersebut terdapat 7 komponen utama yang menunjukkan tahapan guna menentukan dan merencanakan implementasi arsitektur dari suatu sistem informasi. Komponen tersebut dapat dilihat pada Gambar 1. Penjelasan tahapan dan hasil setiap tahapan Gambar 1 ditunjukkan pada Tabel 1.

Tabel 1. Tahapan dan hasil dari EAP

\begin{tabular}{|c|c|c|}
\hline Lapisan & Tahapan & Hasil \\
\hline 1 & Inisiasi perencanaan & $\begin{array}{l}\text { Ruang lingkup, sasaran, visi, penentuan metedologi dan alat-alat } \\
\text { yang akan digunakan, perencanaan tim, persentasi, dan rencana } \\
\text { kerja. }\end{array}$ \\
\hline 2 & $\begin{array}{l}\text { Pemodelan proses bisnis dan } \\
\text { teknologi saat ini }\end{array}$ & $\begin{array}{l}\text { Struktur organisasi, model fungsi bisnis awal, perlengkapan } \\
\text { model bisnis fungsional, katalog sumber daya informasi } \\
\text { (Information Resource Catalog, IRC), dan skema sistem. }\end{array}$ \\
\hline 3 & $\begin{array}{l}\text { Arsitektur data, arsitektur } \\
\text { aplikasi dan arsitektur } \\
\text { teknologi }\end{array}$ & $\begin{array}{l}\text { Pendefinisian entitas, Entity Relationship Diagram (ERD), matrik } \\
\text { entitas terhadap fungsi, dokumen arsitektur data, pendefinisan } \\
\text { aplikasi, materi aplikasi, dokumen arsitektur aplikasi, distribusi } \\
\text { data/aplikasi. }\end{array}$ \\
\hline 4 & Rencana implementasi & $\begin{array}{l}\text { Peningkatan organisasi, kebijakan-kebijakan, standar, prosedur- } \\
\text { prosedur, rencana terperinci. }\end{array}$ \\
\hline
\end{tabular}

\subsection{Analisis SWOT}

SWOT (Strength Weaknes Opportunity Threat) berguna untuk merumuskan strategi organisasi dari suatu perusahaan secara sistematis. Analisis ini bermaksud untuk memaksimalkan kekuatan dan peluang serta meminimalkan kelemahan dan ancaman. Analisa SWOT dibuat agar pengembang sistem ke depan akan lebih terarah dan terencana. Untuk analisis SWOT dapat dilihat pada Tabel 2.

Tabel 2. SWOT

\begin{tabular}{|c|c|c|}
\hline Internal external & Strength & Weakness \\
\hline \multirow{3}{*}{ Penjualan } & $\begin{array}{l}\text { - Sumber daya manusia yang memiliki } \\
\text { pemahaman mengenai TI. } \\
\text { - Pengelolaan distribusi yang } \\
\text { memfasilitasi supplier. }\end{array}$ & $\begin{array}{l}\text { Hampir secara keseluruhan sistem yang } \\
\text { digunakan manual. }\end{array}$ \\
\hline & Opportunity & Threat \\
\hline & $\begin{array}{l}\text { Adanya kerjasama dengan perusahaan- } \\
\text { perusahaan dalam negeri maupun luar } \\
\text { negeri untuk sistem penjualannya. }\end{array}$ & $\begin{array}{l}\text { - Perusahan lain menurunkan harga } \\
\text { penjualan. } \\
\text { - Cuaca yang buruk untuk supplier sehingga } \\
\text { menyebabkan kurangnya nilai penjualan. }\end{array}$ \\
\hline
\end{tabular}

\subsection{Value chain}

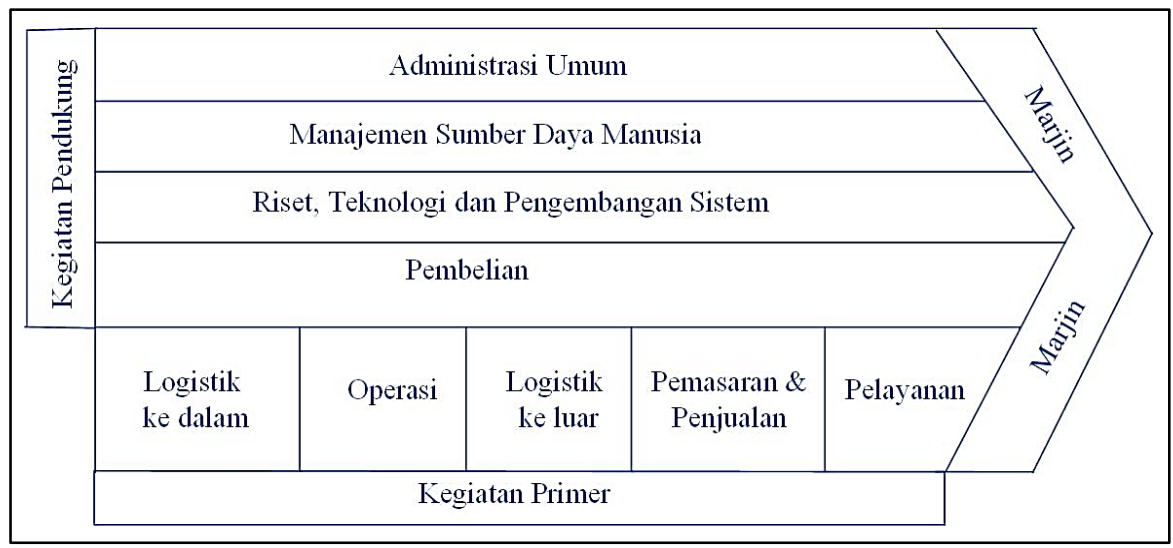

Gambar 2. Value chain (Porter, 1985)

Value chain merupakan gabungan dari suatu rangkaian aktifitas yang mengidentifikasikan lingkungan bisnis dengan mengklasifikasikan bisnis utama (primary activites) dan bisnis pendukung (support activities) guna menciptakan suatu nilai yang dapat menghasilkan keuntungan bagi perusahaan. Perusahaan menunjukan hubungan antara aktivitas dan fungsi yang dilakukan oleh perusahaan yang diubah menjadi keunggulan kompetitif. Ilustrasi value chain dapat dilihat pada Gambar 2. 


\subsection{Proses bisnis}

Proses bisnis yang ada pada PT. KCBS yaitu:
a. Order penjualan
Pada proses tersebut, staf akan memasukan data informasi mengenai penjualan.

b. Order yang terjual

Staf bagian pembelian akan mengesahkan proses pembelian.

c. Cetak order pernjualan

Staf administrasi pembelian akan mencetak bukti transaksi lalu diarsipkan ke pemimpinan.

d. Pembayaran ke supplier

Bagian keuangan melakukan proses pembayaran secara langsung kepada supplier secara tunai.

e. Pembayaran dari mitra kerja

Pihak keuangan menerima uang masuk dalam bentuk nontunai (transfer) melalui pihak bank yang dikirim ke rekening perusahaan.

f. Penerimaan barang

Bagian gudang yang menerima barang, memasukan datanya, dan harus mencocokan barang yang diterima dari proses penjualan dan pembelian.

\section{Metode Penelitian}

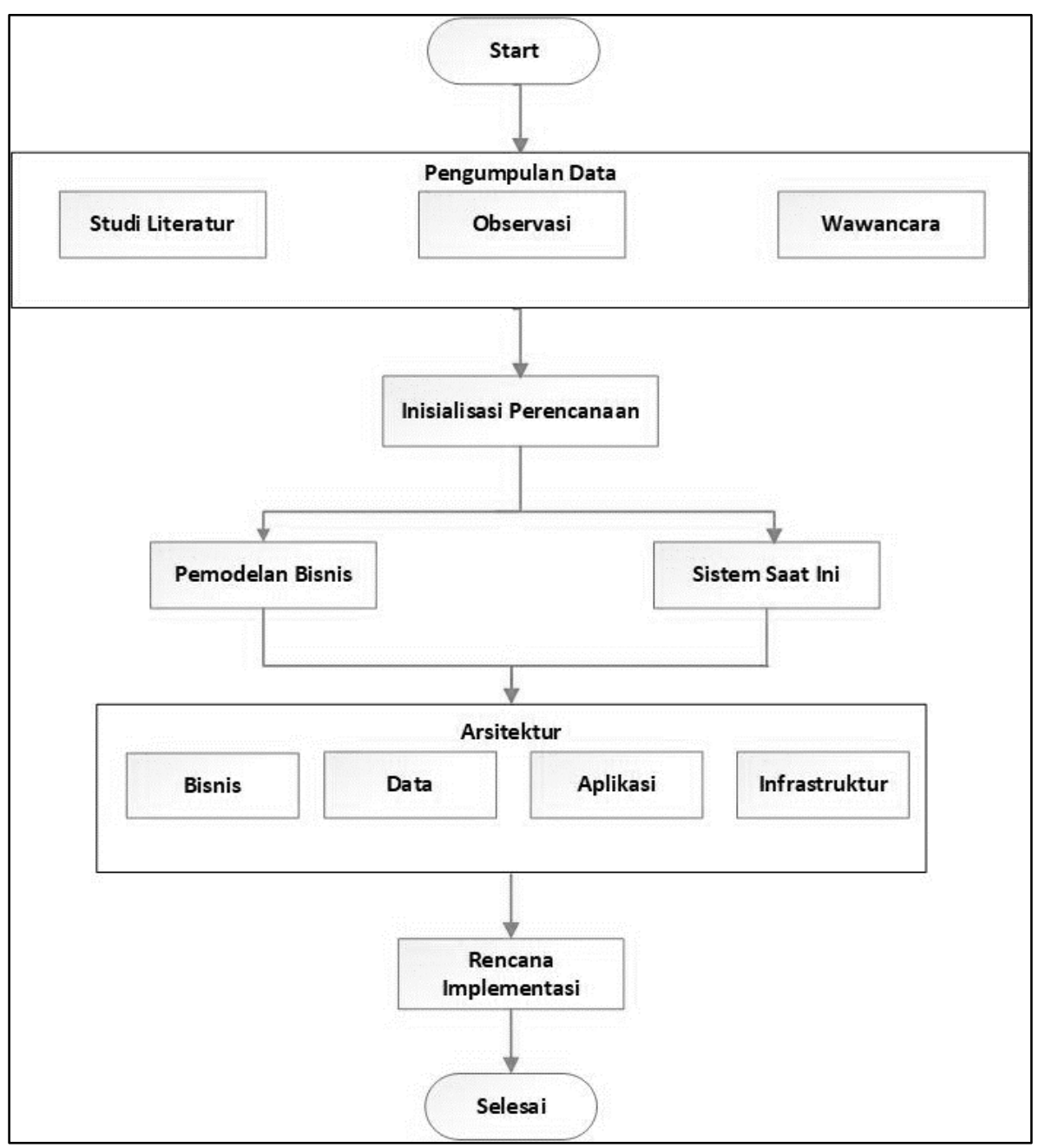

Gambar 3. Flowchart penelitian

Penelitian ini memiliki tahapan seperti pada Gambar 3. Pengumpulan data dilakukan dengan berbagai cara, baik studi literatur, observasi, dan wawancara. Wawancara dilakukan kepada pimpinan perusahaan dan karyawan yang dianggap terlibat dalam proses bisnis tersebut. Studi literatur dilakukan pada beberapa jurnal yang dijadikan sebagai sumber referensi karena dianggap ada kaitannya dengan topik yang dibahas. Observasi dilakukan dengan cara melakukan pengamatan secara langsung di perusahaan tersebut. Inisialisasi perencanaan dilakukan dengan cara menganalis 
pemodelan bisnis dan sistem saat ini yang sedang berjalan pada perusahaan dengan sistem manual. Penerapan arsitektur terdiri dari bisnis dari perusaahaan, data, aplikasi dan infrastruktur. Langkah terakhir adalah dilakukan rencana implementasi.

\section{Hasil dan Pembahasan}

\subsection{Pemodelan bisnis}

Pemodelan bisnis merupakan proses lintas fungsional, biasanya penggabungan pekerjaan dan dokumentasi lebih dari satu departemen dalam sebuah organisasi atau perusahaan. Hasil dari pemodelan proses bisnis pada dasarnya adalah nilai tambah pelanggan, mengurangi biaya perusahaan, menyebabkan peningkatan pada keuntungan. Pada penelitian ini, pemodelan bisnis yang digunakan oleh PT. KCBS yaitu menggunakan analisis value chain. Tujuan dari penggunaan value chain yaitu untuk mengetahui jenis-jenis kegiatan serta aktifitas yang ada dalam PT. KCBS. Dalam analisis value chain terdapat 2 aktifitas, yaitu aktifitas utama (main activites) dan aktifitas pendukung (support activites). Ilustrasi value chain diperlihatkan pada Gambar 4.

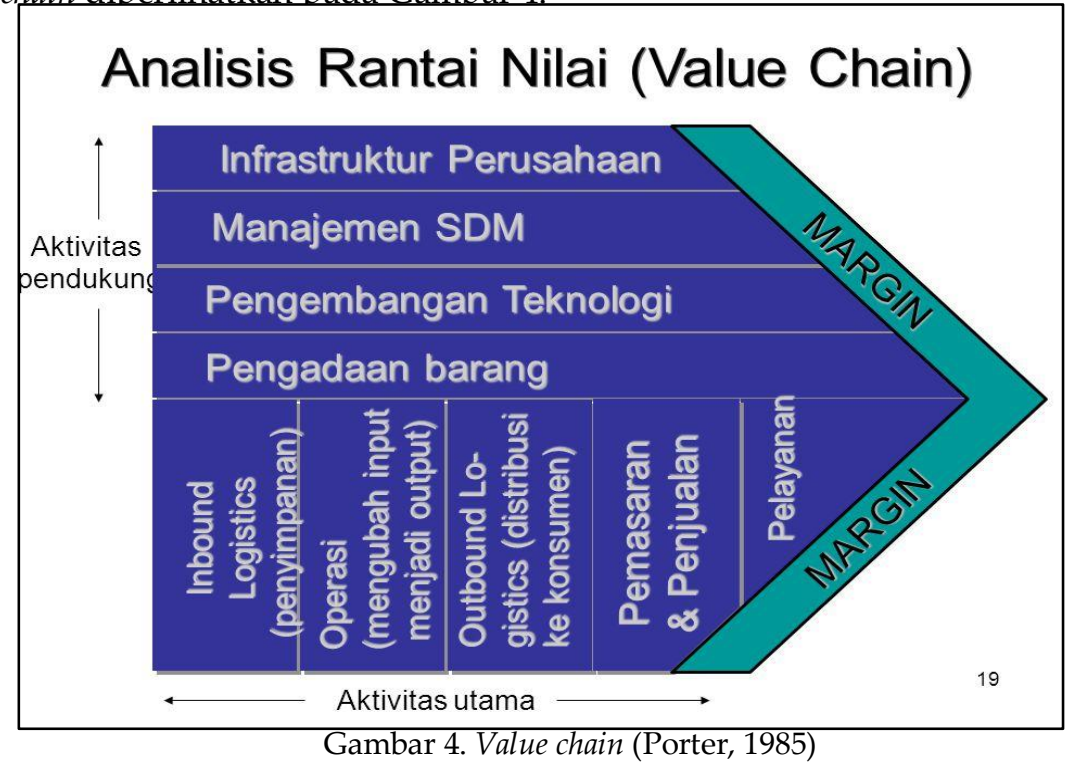

Gambar 4 memiliki aktifitas pendukung, diantaranya adalah: Infrastruktur perusahaan, managemen SDM, pengembangan teknologi, pengadaan barang. Sedangkan yang termaksud dalam aktifitas utama yaitu: Operasi, distribusi ke konsumen, pemasaran, penjualan dan pelayanan.

\subsection{Sistem saat ini}

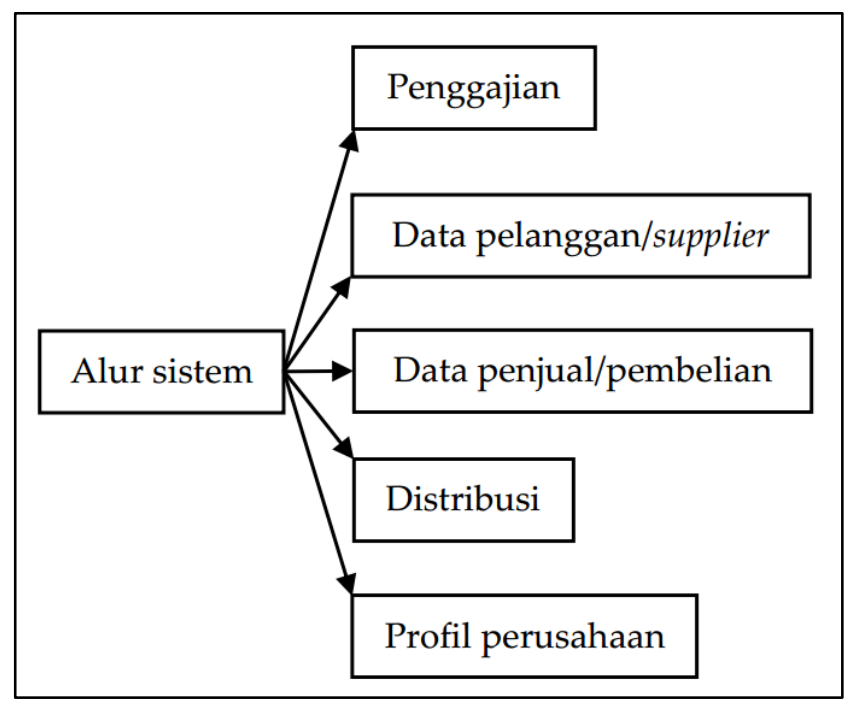

Gambar 5. Sistem saat ini

Sampai pada saat ini, sistem yang diterapkan pada perusahaan PT. KCBS belum menerapkan TI secara maksimal untuk mendukung proses bisnis. Gambar 5 memperlihatkan bahwa PT. KCBS belum 
memanfaatkan TI secara maksimal. Sementara untuk perawatan sistem yang adapun belum dilaksanakan secara berkala. Apabila terdapat sistem yang bermasalah dan perlu diperbaiki, tidak secara langsung diperbaiki sehingga dapat berakibat pada aktifitas bisnis yang ada. Hal ini berdampak pada digunakannya kembali sistem secara manual.

\subsection{Arsitektur data}

Arsitektur data dibuat untuk mendefinisikan entitas data utama yang digunakan untuk mendukung fungsi bisnis yang ada pada PT. KCBS. Hal pertama yang dilakukan pada arsitektur data adalah pendefinisian entitas data, setelah itu dibuat relasi antara entitas, dan yang terakhir yaitu dibuat matrik proses bisnis terhadap entitas data yang ada. Tabel 3 merupakan rincian entitas bisnis yang ada pada perusahaan PT. KCBS.

Tabel 3. Arsitektur data

\begin{tabular}{ll}
\hline \multicolumn{1}{c}{ Entitas bisnis } & \multicolumn{1}{c}{ Entitas data } \\
\hline Order penjualan & Entitas pelanggan \\
& Entitas barang \\
& Entita harga \\
& Entitas stok \\
& Entitas Pelanggan \\
Order yang terjual & Entitas barang \\
& Entitas surat jalan \\
Cetak order penjualan & Entitas pelanggan \\
& Entitas barang \\
& Entitas harga \\
Pembayaran ke supplier & Entitas barang \\
& Entitas harga \\
Pambayaran dari mitra kerja & Entitas barang \\
& Entitas harga \\
Penerimaan barang & Entitas barang \\
& Entitas stok \\
\hline
\end{tabular}

\subsection{Arsitektur aplikasi}

Tabel 4. Arsitektur aplikasi

\begin{tabular}{|c|c|c|c|}
\hline Aktivitas & Kebutuhan & Usulan SI/TI & Keterangan \\
\hline Proses penjualan & $\begin{array}{l}\text { Membutuhkan sistem informasi } \\
\text { yang dapat memonitor proses } \\
\text { penjualan. }\end{array}$ & $\begin{array}{l}\text { Sistem Informasi } \\
\text { Monitoring }\end{array}$ & $\begin{array}{l}\text { Mengembangkar } \\
\text { kebutuhan yang } \\
\text { sudah ada }\end{array}$ \\
\hline Marketing & $\begin{array}{l}\text { Membutuhkan website untuk } \\
\text { proses penjualan secara online. }\end{array}$ & $e$-Business & Pembuatan baru \\
\hline Pengelolaan keuangan & $\begin{array}{l}\text { Membutuhkan suatu aplikasi yang } \\
\text { dapat mengelola sistem keuangan, } \\
\text { panggajian, dan pembayaran. }\end{array}$ & $\begin{array}{l}\text { Sistem Informasi } \\
\text { Keuangan }\end{array}$ & Pembuatan baru \\
\hline $\begin{array}{l}\text { Sumber Daya Manusia } \\
(\mathrm{SDM})\end{array}$ & $\begin{array}{l}\text { Membutuhkan sistem informasi } \\
\text { untuk mengelola data karyawan. }\end{array}$ & $\begin{array}{l}\text { Sistem Informasi } \\
\text { Kepegawaian }\end{array}$ & $\begin{array}{l}\text { Pengembangan } \\
\text { sistem lama }\end{array}$ \\
\hline Gudang & $\begin{array}{l}\text { Membutuhkan sistem informasi } \\
\text { untuk mengelola stok barang yang } \\
\text { ada di perusahaan. }\end{array}$ & $\begin{array}{l}\text { Sistem Informasi } \\
\text { Gudang }\end{array}$ & $\begin{array}{l}\text { Pengembangan } \\
\text { sistem lama }\end{array}$ \\
\hline Supplier & $\begin{array}{l}\text { Membutuhkan sistem informasi } \\
\text { untuk mengelola data supplier. }\end{array}$ & $\begin{array}{l}\text { Sistem Informasi } \\
\text { Supplier }\end{array}$ & $\begin{array}{l}\text { Pengembangan } \\
\text { sistem lama }\end{array}$ \\
\hline Pelayanan & $\begin{array}{l}\text { Membutuhkan web profil } \\
\text { perusahaan untuk meningkatkan } \\
\text { pelayanan kepada pelanggan }\end{array}$ & $\begin{array}{l}\text { Web profil } \\
\text { perusahaan }\end{array}$ & Pembuatan baru \\
\hline
\end{tabular}

Tujuan arsitektur aplikasi yaitu agar dapat mendefinisikan aplikasi utama yang digunakan untuk mendukung proses bisnis dari perusahan tersebut. Tahapan ini dilakukan daftar kandidat aplikasi dan 
definisi dari aplikasi sistem informasi. Sementara untuk kandidat aplikasi dapat diperoleh dari hasil analisis yang telah dilakukan. Penentuan kandidat aplikasi digunakan analisis value chain. Kandidat aplikasi adalah usulan sistem informasi yang akan datang. Arsitektur aplikasi diperlihatkan pada Tabel 4 .

Berdasarkan Tabel 4 terdapat 7 usulan sistem informasi yang akan dikembangkan. Sistem informasi tersebut antara lain: Sistem Informasi Penjualan, Sistem Informasi Marketing, Sistem Informasi Pengelolaan Keuangan, Sistem Informasi Kepegawaian, Sistem Informasi Gudang, Sistem Informasi Supplier, Dan Sistem Informasi Pelayanan.

\section{Rencana Implementasi}

Implementasi arsitektur enterprise dibuat untuk sistem informasi dan pengembangan sistem yang ada pada saat ini. Pengembangan aplikasi juga dibutuhkan untuk perencanaan beberapa tahap ke depan. Pengembangan aplikasi disesuaikan dengan kebutuhan perusahaan. Tabel 5 merupakan gambaran aplikasi strategis.

Tabel 5. Rencana implementasi

\begin{tabular}{ll}
\hline \multicolumn{1}{c}{ Strategi } & \multicolumn{1}{c}{ Berpotensi tinggi } \\
\hline Penjualan & Aplikasi Penjualan \\
Sistem Informasi SDM & Sistem Informasi Kepegawaian \\
Sistem Informasi Pelayanan & Web profil perusahaan \\
Sistem Informasi Supplier & Sistem Informasi Supplier \\
Sistem Informasi Keuangan & Sistem Informasi Keuangan
\end{tabular}

Berdasarkan Tabel 5 sistem informasi telah dipetakan sesuai dengan posisi dan kebutuhan perusahaan. Sistem informasi bersifat strategis yaitu yang bersifat kristis untuk kelanjutan bisnis di masa depan. Sistem informasi yang termasuk dalam strategis antara lain, Sistem Informasi Penjualan, SDM, Pelayanan, Supplier, dan Keuangan.

Sistem informasi yang berpotensi tinggi yaitu sistem yang mungkin penting untuk mencapai kesuksesa. Sistem informasi yang berpotensi tinggi antara lain, aplikasi penjualan, Sistem informasi karyawan, Web profil perusahaan, sistem informasi supplier dan sistem informasi keuangan. Usulan atau rekomendasi sistem informassi tersebut ditunjukan untuk manager perusahaan terkait sesuai dengan visinya.

\section{Kesimpulan}

Berdasarkan penelitian yang dilakukan dapat disimpulkan bahwa penerapan EAP merupakan sebuah strategi holistik yang digunakan untuk meningkatkan penyelarasan bisnis dan TI pada perusahaan, serta sebagai keunggulan kompetetif. EAP dapat mengidentifikasi proses bisnis sampai pada rencana implementasi sistem informasi. Proses bisnis terdapat aktifitas utama yang meliputi penjualan, keuangan dan supplier, sementara untuk aktifitas pendukung yaitu SDM, gudang dan pelayanan.

Berdasarkan hasil analisis melalui beberapa tahapan pada aktivitas utama dan aktivitas pendukung, maka didapatkan portofolio aplikasi sistem informasi pada PT. KCBS diantaranya: Sistem Informasi Kepegawaian, Sistem Informasi Penjualan, Sistem Informasi Keuangan, Sistem Infomasi Supplier, Sistem Informasi Gudang, dan Sistem Informasi Pelayanan dalam bentuk web profil perusahaan. Hasil ini diharapkan agar proses bisnis dari perusahan PT. KCBS berjalan lebih efektif.

Arsitektur yang dibuat merupakan kondisi yang nantinya ingin dicapai dari perusahaan tersebut, akan tetapi yang menjadi penghambat dalam pelaksanaan identifikasi proses bisnis yaitu aturan dan kultur dari perusahan tersebut. Keuntungan dari EAP yaitu dapat meningkatkan misi, fungsi, dan landasan bisnis untuk mendukung perencanaan dan pengambilan keputusan yang baik, serta memperbaiki komunikasi di antara organisasi TI dan mempercepat integrasi sistem yang eksis.

\section{Referensi}

Budiyanto, D., \& Setyohadi, D. B. (2017). Strategic information system plan for the implementation of information technology at Polytechnic "API" Yogyakarta. 2017 5th International Conference on Cyber and IT Service Management (CITSM). Denpasar: IEEE.

Gomes, R. (2015). Resilience and enterprise architecture in SMES. JISTEM - Journal of Information Systems and Technology Management, 12(3), 525-540. 
Hinkelmann, K., \& Pasquini, A. (2014). Supporting Business and IT Alignment by Modeling Business and IT Strategy and its Relations to Enterprise Architecture. 2014 Second International Conference on Enterprise Systems (pp. 149-154). Shanghai: IEEE.

Korhonen, J. J., \& Molnar, W. A. (2014). Enterprise Architecture as Capability: Strategic Application of Competencies to Govern Enterprise Transformation. 2014 IEEE 16th Conference on Business Informatics (pp. 175-182). Geneva: IEEE.

Kristanto, T. (2016). Enterprise Architecture Planning Untuk Proses Pengelolaan Manajemen Aset Dengan Zachman Framework. Register: Jurnal Ilmiah Teknologi Sistem Informasi, 2(2), 98-104.

Kurniawan, N. B., \& Suhardi, S. (2013). Enterprise Architecture design for ensuring strategic business IT alignment (integrating SAMM with TOGAF 9.1). 2013 Joint International Conference on Rural Information \& Communication Technology and Electric-Vehicle Technology (rICT \& ICeV-T). Bandung: IEEE.

Lin, F., \& Dyck, H. (2010). The Value of Implementing Enterprise Architecture in Organizations. Journal of International Technology and Information Management, 19(1), 1.

Mezzanotte, D. M., \& Dehlinger, J. (2014). Developing and building a quality management system based on stakeholder behavior for enterprise architecture. 15th IEEE/ACIS International Conference on Software Engineering, Artificial Intelligence, Networking and Parallel/Distributed Computing (SNPD). Las Vegas: IEEE.

Mualo, A., \& Budiyanto, A. D. (2016). Perencanaan strategis sistem informasi menggunakan TOGAF (Studi kasus: Universitas Satria Makassar). Seminar Riset Teknologi Informasi (SRITI) (pp. 294-304). Yogyakarta: STMIK AKAKOM.

Nikpay, F., Ahmad, R. B., Rouhani, B. D., Mahrin, M. N., \& Shamshirband, S. (2017). An effective Enterprise Architecture Implementation Methodology. Information Systems and e-Business Management, 15(4), 927-962.

Porter, M. E. (1985). The Competitive Advantage: Creating and Sustaining Superior Performance. New York: Free perss.

Rajabi, Z., \& Abade, M. N. (2012). Data-Centric Enterprise Architecture. International Journal of Information Engineering and Electronic Business (IJIEEB), 4(4), 53-60.

Riku, M. O., \& Setyohadi, D. B. (2017). Strategic plan with enterprise architecture planning for applying information system at PT. Bestonindo Central Lestari. 2017 5th International Conference on Cyber and IT Service Management (CITSM). Denpasar: IEEE.

Simon, D., Fischbach, K., \& Schoder, D. (2014). Enterprise architecture management and its role in corporate strategic management. Information Systems and e-Business Management, 12(1), 5-42.

Spewak, S. H., \& Hill, S. C. (1993). Enterprise architecture planning: developing a blueprint for data, applications and technology. Enterprise architecture planning: developing a blueprint for data, applications and technology. Boston: QED Information Sciences.

Wiyana, W., \& Winarno, W. W. (2015). Sistem Panjaminan Mutu Pendidikan Dengan TOGAF ADM Untuk Sekolah Menengah Kejuruan. Register: Jurnal Ilmiah Teknologi Sistem Informasi, 1(1), 7-14. 